- RAM, REV. ADM. MACKENZIE, 16(3), Edição Especial • SÃO PAULO, SP • MAIO/JUN. 2015 • ISSN 1518-6776 (impresso) • ISSN 1678-6971 (on-line) • http://dx.doi.org/10.1590/1678-69712015/administracao.v16n3p171-200. Submissão: 24 abr. 2014. Aceitação: 19 ago. 2014.

Sistema de avaliação: às cegas dupla (double blind review).

UNIVERSIDADE PRESBITERIANA MACKENZIE. Silvio Popadiuk (Ed.), Ana Sílvia Rocha Ipiranga (Ed. Seção), p. 171-200.

\title{
1 AS RELAÇÕES SIMBÓLICAS E A MOTIVAÇÃO NO TRABALHO VOLUNTÁRIO
}

\section{KÁSSIA DE AGUIAR SALAZAR}

Mestra em Administração pelo Centro de Ciências Jurídicas e Econômicas

da Universidade Federal do Espírito Santo (Ufes).

Avenida Fernando Ferrari, 514, CCJE/Departamento de Administração, Goiabeiras,

Vitória - ES - Brasil - CEP 29075-910

E-mail: kassia.salazar@yahoo.com.br

\section{ALFREDO RODRIGUES LEITE DA SILVA}

Doutor em Administração pela Faculdade de Ciências Econômicas da Universidade Federal de Minas Gerais (UFMG).

Professor adjunto do Departamento de Administração da Universidade Federal do Espírito Santo (Ufes).

Avenida Fernando Ferrari, 514, CCJE/Departamento de Administração, Goiabeiras, Vitória - ES - Brasil - CEP 29075-910

E-mail: alfredoufes@gmail.com

\section{LETÍCIA DIAS FANTINEL}

Doutora em Administração pela Escola de Administração da Universidade Federal da Bahia (Ufba).

Professora adjunta do Departamento de Administração da Universidade Federal do Espírito Santo (Ufes).

Avenida Fernando Ferrari, 514, CCJE/Departamento de Administração, Goiabeiras,

Vitória - ES - Brasil - CEP 29075-910

E-mail: leticiafantinel@gmail.com

Este artigo pode ser copiado, distribuído, exibido, transmitido ou adaptado desde que citados, de forma clara e explícita, o nome da revista, a edição, o ano e as páginas nas quais o artigo foi publicado originalmente, mas sem sugerir que a RAM endosse a reutilização do artigo. Esse termo de licenciamento deve ser explicitado para os casos de reutilização ou distribuição para terceiros. Não é permitido o uso para fins comerciais. 


\section{RESUMO}

O objetivo deste artigo é compreender as relações simbólicas que envolvem a motivação no trabalho voluntário. A parte empírica do artigo tem como locus a Associação Voluntárias da Apae (Avapae) de Venda Nova do Imigrante. O artigo se legitima na relevância de estudar as organizações por meio de abordagens voltadas para os simbolismos organizacionais (Morgan, Frost, \& Pondy, I983; Gioia, I986; Carrieri \& Saraiva, 2007). Neste artigo, isso se realiza pelo reconhecimento da relação entre a construção social da realidade (Berger \& Luckmann, I985) dos voluntários e suas representações da motivação com base em uma subjetividade (Rey, 2005) articulada nas especificidades do trabalho voluntário. Os dados empíricos foram coletados por meio de I4 entrevistas semiestruturadas com voluntários da Avapae, observação não participante durante três meses no local de trabalho dos voluntários e análise de documentos. Os dados foram tratados com base na técnica de análise de conteúdo. Para as voluntárias estudadas, o trabalho está relacionado com a capacidade de, por meio de um bordado, por exemplo, produzirem-se significados, como ajudar o próximo, divertir-se, mudar a rotina, entre outros. A motivação, observada por meio dos significados da participação voluntária, tem como base o sentimento de fazer parte de algo ou de transformar um meio, tendo um papel importante naquela tarefa social (Palassi \& Vervloet, 20II). A pesquisa evidenciou o contexto da Avapae como complexo permeado por múltiplos simbolismos e subjetividades, com destaque para as construções sociais oriundas dos moradores de Venda Nova do Imigrante, além dos limites da organização estudada. O venda-novense configurou-se como produto e produtor de parte dos simbolismos que envolvem a motivação para o voluntariado. Como contribuição final deste trabalho, defende-se que os caminhos para tratar da motivação para o voluntariado devem considerar a ação dos atores socais e os seus contextos de inserção em termos das trocas simbólicas vivenciadas na organização e na sociedade mais ampla, como foi observado na comunidade venda-novense. 


\section{PALAVRAS-CHAVE}

Simbolismo organizacional. Motivação. Trabalho. Voluntário. Subjetividade.

\section{INTRODUÇÃO}

Este artigo se legitima na relevância de desenvolver pesquisas com base no simbolismo organizacional, dentro do paradigma interpretativista, sobre o tema da motivação no trabalho voluntário. No campo do simbolismo organizacional, comumente, esse tema não é tratado de maneira específica, o que coloca em segundo plano a importância de se tratar das trocas simbólicas dos atores sociais, em seus múltiplos contextos de inserção (organizacionais e locais), ao se estudar a motivação no trabalho voluntário. Com o intuito de contribuir para preencher essa lacuna, este artigo defende que a motivação do voluntário se constrói em uma dinâmica própria, marcada pelo conjunto de contextos e grupos sociais que envolvem uma organização específica.

Segundo Burrell e Morgan (I979) e Morgan, Frost e Pondy (I983), os pesquisadores interpretativistas buscam entender a experiência subjetiva da organização e de seus membros por meio de um estudo em que a realidade social é vista como um processo emergente, construído na experiência social dos sujeitos dentro e fora do meio organizacional.

Em conjunto com esse entendimento, articula-se aqui a teoria da subjetividade de Rey (2005), para quem o sujeito não está isolado do contexto em que vive ou trabalha, mas também não é apenas produção do meio. A subjetividade não pode ser controlada, racionalizada ou prevista, mas pode ser entendida como produção de sentidos. É com base nesses sentidos que ela é organizada em torno das necessidades na relação direta indivíduo-contexto, bem como pela bagagem histórico-social que o indivíduo traz consigo (Rey, 2005; Paes De Paula \& Palassi, 2007).

Para que essa dinâmica possa ocorrer, como explicam Berger e Luckmann (I985, p. 60), a linguagem organiza o meio pelas construções de "edifícios" de representações simbólicas. Assim, a linguagem simbólica e o simbolismo tornam-se componentes básicos da construção social da realidade cotidiana. As pessoas vivem, pois, em um mundo de símbolos e sinais em constante construção social (Cavedon \& Fachin, 2008). Esse é um processo a partir do qual as organizações podem ser consideradas como um conjunto de pessoas que criam e recriam suas relações simbólicas, dinâmica que interfere em suas atividades (Turner, I990). 
Com base nesse entendimento, este estudo se volta para o seguinte objetivo: compreender as relações simbólicas que envolvem a motivação no trabalho voluntário. A parte empírica do estudo tem como locus a Associação Voluntárias da Apae (Avapae) e Venda Nova do Imigrante, um município do Estado do Espírito Santo. Tal objetivo parte da premissa teórica de que, a partir do simbolismo organizacional, é possível acessar aspectos simbólicos que envolvem a motivação das pessoas para a realização do seu trabalho, proporcionando a compreensão sobre o que envolve os desejos e as necessidades das pessoas em suas relações no ambiente organizacional (Cavalcanti, Medeiros, Moreira Neto, Oliveira, \& Souza, 20II).

Sob um olhar interpretativista, a motivação é tratada como algo complexo, individual e social, informal e subjetivo. Neste trabalho, parte-se do princípio de que a conceituação de motivação é diversa e heterogênea. Não há consenso entre os autores sobre o conceito ou mesmo sobre os fatores que possibilitam a efetivação da motivação do homem. Entre os diversos conceitos propugnados, há somente certa tendência comum em indicar que a motivação trata do que mobiliza a pessoa a realizar algo, a partir da articulação de motivos e desejos (Sampaio \& Morávia, 2009).

Visto que este artigo assume uma perspectiva subjetiva, baseada na abordagem interpretativista, a motivação e a realização do trabalho pelo homem são tratadas como construções sociais que ocorrem influenciadas por construções anteriores e que, ao mesmo tempo, interferem na construção do ambiente social. Parte-se do pressuposto que é desse processo que surge a motivação para realizar algo, na medida em que o indivíduo está construindo a sua obra (Balsan, Campos, \& Fossá, 2OII).

Essa obra, no caso do trabalho voluntário, foco deste artigo, reveste-se de particularidades típicas em relação ao que motiva um indivíduo a fazer parte de um grupo para ajudar outras pessoas voluntariamente, como a abdicação da recompensa material em favor de recompensas intangíveis (Cavalcanti \& Medeiros, 2007).

Sob as luzes de uma abordagem interpretativista, aqui adotada, essa motivação baseia-se em uma rede de jogos simbólicos que definem muitos modos diferentes de perceber a realidade socialmente construída (Berger \& Luckmann, I985). A tarefa da análise simbólica, quando abordada sobre a base da metáfora de um jogo de linguagem, é entender como realidades sociais são encenadas por meio de diferentes contextos (Morgan et al., I983). Carrieri e Saraiva (2007) explicam que, em vez de se buscar entender o mundo dito real, que existiria independentemente do indivíduo, procura-se compreender o que as coisas ditas reais significam para o homem. Ou seja, exploram-se as relações construídas pelo indivíduo para entender o ambiente em que ele se insere. Tal perspectiva almeja 
estudar o que acontece em uma organização de forma profunda e detalhada, humanizando o contexto organizacional, aproximando-se da complexidade do cotidiano dos sujeitos ali envolvidos.

Os dados empíricos utilizados para compreender como as relações simbólicas envolvem a motivação do trabalho foram coletados por meio de I4 entrevistas semiestruturadas com voluntários da Avapae, observação não participante durante três meses no local de trabalho dos voluntários e análise de documentos. Os dados foram tratados com base na técnica de análise de conteúdo.

Os dados evidenciam um processo de produção de sentido, por parte das voluntárias, por meio do rearranjo de suas histórias sociais subjetivas, que se entrelaçam em torno do valor de ser voluntário no seu ambiente social. O contexto social da Avapae e do município de Venda Nova do Imigrante demonstrou-se propício ao voluntariado a partir de articulações relacionadas com a história, a cultura, os hábitos, os valores e as imagens presentes no imaginário local, manifestados pelos atores sociais inseridos nesses contextos. O cidadão venda-novense, como ator social, é produto e produtor de simbolismos que envolvem o voluntariado no município, para além do contexto da Avapae, visto que a motivação das voluntárias da associação inclui aspectos que se manifestam em rebatimentos de histórias de vida associadas à história do município e das famílias lá estabelecidas ao longo dos anos.

Para desenvolver essa discussão, o presente artigo foi estruturado da seguinte maneira: primeiramente, abordam-se aspectos relacionados ao campo do simbolismo organizacional interpretativo; em seguida, a fim de posicionar a perspectiva interpretativa nos estudos da motivação do trabalho em geral e, especificamente, do trabalho voluntário, apresenta-se uma delimitação dos estudos sobre o tema; com base na articulação dessas contribuições teóricas, os dados empíricos coletados na Avapae são confrontados na análise; por fim, são apresentadas as considerações finais do estudo.

\section{O CAMPO DO SIMBOLISMO ORGANIZACIONAL INTERPRETATIVO}

O sentido de estudar o simbolismo organizacional procede do reconhecimento de que entender os significados que envolvem o contexto organizacional é importante, pois as organizações não são sistemas simples como organismos adaptativos ou máquinas, mas sim sistemas humanos que se manifestam em padrões complexos de atividade cultural. Morgan et al. (I983) reforçam que as pessoas são capazes de usar a linguagem, produzir, apresentar uma visão e que, igualmente, elas constroem significados sobre os eventos nas organizações, bem 
como interpretam metáforas, comportamentos e objetos, enfim, buscam sentido para suas vidas, agindo simbolicamente. A partir disso, entende-se que as pessoas constroem definições de uma realidade nas organizações tendo como base a construção simbólica, que serve como direcionadora para compreender esse contexto e agir sobre ele (Carrieri \& Saraiva, 2007; Cavedon \& Fachin, 2008; Gioia, I986). Símbolos são, portanto, um caminho para entender as sucessivas transformações no ambiente organizacional. Turner (I990) acrescenta, nessa discussão, o fato de que um único símbolo organizacional pode ter múltiplas implicações, dependendo de como ele foi socialmente construído. Morgan et al. (I983) afirmam ainda que os símbolos surgem quando vestem os indivíduos com aspectos de seu mundo a partir de um padrão particular de significado subjetivo.

Considerar o simbolismo interpretativo é uma forma de abrir os horizontes nas pesquisas em administração, pois, além de aspectos formais, os estudos em organizações se deparam com a impossibilidade de objetivar tudo, principalmente no que tange aos aspectos sociais. Enfim, estudos interpretativos não almejam a inexistência de instâncias objetivas e formalizadas no meio organizacional, contudo há que se destacar que tais aspectos são apenas "a ponta do iceberg", pois as referidas instâncias não conseguem esgotar a imensa complexidade das relações cotidianas nas organizações (Carrieri \& Saraiva, 2007).

A partir dessa compreensão da necessidade de dar sentido à experiência subjetiva da organização e de seus membros, pesquisadores, sob o paradigma interpretativo, buscam entender como é feita a construção da realidade em um contexto organizacional. De acordo com Burrell e Morgan (I979), as teorias do paradigma interpretativo são construídas do ponto de vista do ator, o trabalhador, em contraposição ao do observador da ação. Os estudiosos dessa vertente entendem a realidade social como um processo emergente, como uma criação e extensão da consciência humana e da experiência subjetiva dos indivíduos envolvidos no meio organizacional. Rey (2005) salienta que o desenvolvimento do sentido subjetivo explica com facilidade a emersão da emoção como convergência do confronto entre os elementos dos sentidos dos sujeitos. Esses elementos constituem a subjetividade do indivíduo como expressão da sua história e de outros aspectos que surgem a partir das suas ações no meio social. Nessa perspectiva, Aktouf (i994) afirma que o trabalhador deveria construir uma identificação com seu trabalho, fato possível somente com a superação da alienação, quando o indivíduo rompe com a ausência de percepção que tem de si mesmo. Essa ruptura levaria o trabalhador a assumir o ato do ofício como seu ato, como sua reabilitação à condição de sujeito. Dessa maneira, esse indivíduo será o parceiro ativo, o ator na construção da sua história e da história da organização, tendo assim desejo de realizar com motivação sua atividade na organização em que trabalha. 


\section{A MOTIVAÇÃO DO TRABALHADOR}

O tema motivação do trabalho tem despertado interesse de diversas áreas do conhecimento, como a psicologia organizacional, psicologia social, administração e sociologia. Tal temática tem sido discutida em vertentes distintas, por exemplo: como um elemento de exploração e de alienação, que gera um sofrimento psíquico do ser humano; ou como um recurso que colabora no desenvolvimento e na conceituação da identidade do homem, fazendo parte da realização pessoal, social e profissional (Herzberg, I997; Cavalcanti et al., 20II).

Nord e Fox (2004) salientam que, no início dos estudos sobre motivação, os teóricos assumiram que a universalização de teorias era possível e que as motivações seriam orientadas individualmente. Não obstante, segundo os autores, mais recentemente, os estudiosos da área perceberam a complexidade inerente ao fenômeno e concluíram que desenvolver generalizações acerca das técnicas de motivação não seria algo relevante ou efetivo nas organizações.

As teorias motivacionais que se baseiam em metodologias generalistas tendem à operacionalização do meio social, tomando como parâmetro a motivação do trabalhador para realizar uma tarefa objetivada e mecanizada. Um exemplo dessa tentativa é a teoria da hierarquia das necessidades, que foi desenvolvida de acordo com a análise psicológica da predominância universalizante de necessidades mais intensas que outras para a realização pessoal, buscando determinar o que motivaria alguém a agir para atender a elas (Maslow, I970).

Também dentro da lógica da generalização, mas indo além das necessidades do indivíduo de Maslow (I970), McClelland (I953) relacionou três conceitos para tratar da temática da motivação: traços (comportamentos consistentes), motivos (meio) e esquemas (personalidade). O autor também baseou sua proposta em três categorias de necessidades: de realização, associação e poder (McClelland, I953; Sampaio, 2004). Outra abordagem comumente citada na área de administração é a teoria da motivação, que McGregor (I970) elaborou como resultado de suas observações sobre o tratamento dispensado por dirigentes a seus subordinados. A partir de tais estudos, ele concebeu sua proposta com base na diferenciação entre o que chamou de teoria $\mathrm{X}$ e teoria $\mathrm{Y}$. Na teoria $\mathrm{Y}$, os dirigentes assumiriam como premissa que o comportamento dos trabalhadores seria positivo e que suas próprias atitudes contribuiriam para que de fato o fosse; e, na teoria $\mathrm{X}$, ao contrário, os dirigentes presumiriam que o comportamento dos trabalhadores seria negativo, e, a partir dessa presunção, eles acabariam por contribuir para que esse comportamento fosse realmente negativo.

Outra proposta, a teoria dos dois fatores de Herzberg (I997), também denominada como teoria da higienização-motivação, volta-se para a identificação de 
dois tipos de aspectos: aqueles capazes de impedir a motivação, classificados como fatores higiênicos; e os capazes de contribuir para que as pessoas se motivem, classificados como fatores motivacionais.

A temática da motivação nos estudos organizacionais, marcada por abordagens generalistas e instrumentais, como as citadas anteriormente, continua sendo estudada e pesquisada, agregando novas dimensões com contribuições das perspectivas cognitivas em psicologia, assim como com o avanço da psicologia humanista. Portanto, percebe-se um movimento de multiplicação de páginas sobre motivação na literatura da psicologia, com uma valorização mais humanista e, em alguns estudos, também interpretativista (Sampaio, 2004).

Bastos, Brandão e Pinho (I997) enfatizam que as visões alternativas para entender as motivações dos trabalhadores se estabelecem a partir dos anos i990, quando surgem escritos que documentam as emergentes perspectivas mais interpretativistas simbólicas, em uma transição do nível macro para o micro. Há um avanço na visão do fenômeno organizacional como uma construção social, baseado na interação entre os indivíduos envolvidos (Berger \& Luckmann, I985; Cavedon \& Fachin, 2008).

O presente artigo enfoca justamente esse corte simbólico ao buscar compreender o que motiva o trabalhador voluntário pelo viés interpretativo e subjetivo. Segundo Rey (2005), a subjetividade está baseada no entendimento histórico-cultural dos sujeitos, em um entrelaçamento do social e do individual. Tais percepções subjetivas são os aspectos motivadores que influenciam os sentidos de participação dos trabalhadores em uma organização.

\section{A PERSPECTIVA INTERPRETATIVA NOS ESTUDOS DA MOTIVAÇÃO DO TRABALHO}

Sob um olhar simbólico interpretativo, compreende-se, para os fins deste artigo, a motivação como algo complexo, individual e social, informal e subjetivo; além disso, entende-se o fenômeno como relacionado a impulsos e necessidades do indivíduo. Por ser a conceituação sobre motivação diversa e heterogênea, não é possível verificar consenso entre os autores sobre o conceito nem sobre os fatores que possibilitam a efetivação da motivação do homem. Somente uma centralidade do conceito motivação é compartilhada: a definição de ser aquilo que mobiliza a pessoa a realizar algo, e essa mobilização para algo é relativa a cada motivo e desejo individual em seus rebatimentos sociais (Sampaio, 2004; Saraiva, 2007). 
Compreende-se, portanto, no contexto da motivação para o trabalho voluntário, que as possibilidades de uma ação coletiva envolvem um elevado grau de complexidade. É por meio dessa mobilização do coletivo que se constroem as relações formais e informais entre os voluntários, o que ocasiona a organização do coletivo e as expressões de conflito. Tal organização entre os trabalhadores, mesmo com os empecilhos do controle social e das novas tecnologias gerenciais, possibilita a resistência à integração dos funcionários ao projeto estruturado pelos dirigentes (Penna, 200I).

O exercício do trabalho nesse ambiente social, quando dotado de sentido para o trabalhador, resulta, portanto, em autorrealização, na medida em que o trabalhador se realiza como ser humano que constrói a própria obra. Tal realização se torna incompatível com o contexto contemporâneo da sociedade, em que o indivíduo vive em um mundo social-econômico que empobrece o ser humano, levando-o a um vazio existencial causado pela busca, sem fim, de suprir as necessidades imediatistas e superficiais da modernidade (Balsan et al., 20II).

Nesse contexto de um complexo vazio existencial do indivíduo, Aktouf (I994) analisa que os processos de reconhecimento social e/ou conformismo dos trabalhadores nas organizações justificam os significados de adaptações à situação de trabalho. O trabalhador pode não apenas contestar as normas dirigentes, em um movimento formado pelo coletivo dessas pessoas, mas também pode ocorrer o contrário: um alinhamento com os valores, as normas e crenças da organização.

Por isso, na construção de regulação interna nas organizações, há distintas práticas que ocorrem nas realizações de trabalho. Essas práticas não são somente voltadas contra os dirigentes da organização; elas se configuram em representações, ações e reações que podem ser convergentes ou divergentes do pensamento dominante. Elas são vivenciadas nas organizações por meio de diferentes formas de socialização, pelas relações em grupo ou intersubjetivas (Carrieri \& Saraiva, 2007).

Para França, Mendes e Siqueira (20II), na construção da história de vida, o indivíduo, baseado nos próprios desejos, busca satisfazer suas ambições, de modo que sonhos e projetos são materializados na ânsia de participar da construção de algo em grupo ou individualmente. O desejo de fazer parte das construções relevantes no contexto social torna-se o sentido e a razão de ser do trabalhador, que dota seu trabalho de outras expressões que não se limitam a uma mera fonte de subsistência.

O significado do trabalho para o indivíduo reside na capacidade de construção de um objeto e de produção de significados para sua obra. O trabalho denota um dos elos nas relações sociais e representa o papel daquele trabalhador na sociedade em que vive. Contudo, a pessoa, antes de ser uma trabalhadora, pertence a um grupo social, no qual passou por processos de socialização baseados em valores 
e crenças dominantes. A influência simbólica dos valores desse grupo social adentra o espaço do trabalho, havendo um entrelaçamento de diversos indivíduos com construções sociais distintas (Carrieri \& Saraiva, 2007; Saraiva, 2007).

As relações entre os trabalhadores e entre o trabalhador e sua atividade são processos que o ator social cria a partir de sua construção social da realidade (Berger \& Luckmann, I985). Quando se analisam os símbolos e significados como artefatos que os atores organizacionais criam, recriam e inventam na dinâmica de edificação de seu mundo social, percebe-se que o fenômeno interfere na realização do trabalho no cotidiano da organização (Cavedon \& Fachin, 2008).

O ser social, portanto, experimenta sua individualidade no campo social. O estatuto de trabalhador, nesse contexto, possibilita o convívio comum e o pertencimento a certos grupos. A sensação de ser produtivo na execução de determinada atividade está ligada diretamente ao sentimento de bem-estar como incentivo para a criação e fonte de estímulo. Isso torna a capacidade desse trabalhador palpável e concreta, o que poderá beneficiar o outro, e, em contrapartida, haverá um reconhecimento social pela atividade realizada (Jaime, 2005).

Assim, Campos e Saraiva (20II) analisam que há a possibilidade de compreender as motivações dos sentimentos, das angústias e dos valores que o trabalhador atribui à sua atividade laboral entendendo quais são as implicações do ato de trabalhar no ambiente organizacional. Com essa visão sobre o fenômeno do trabalho na sociedade, tendo como foco de análise suas dimensões plurais, uma nova perspectiva de reflexão surge sobre as relações de trabalho.

A partir desse novo olhar subjetivo e simbólico para entender a relação entre indivíduo e organização, emergem estudos sobre o trabalho com o foco na compreensão das formas de individuação e subjetivação dos trabalhadores, em uma abordagem interpretativa. Nessa perspectiva, escolhe-se compreender, por meio da visão do trabalhador, os fenômenos do trabalho com foco na motivação para a participação voluntária.

Palassi \& Vervloet (20II) discutem o fenômeno da motivação por meio dos sentidos da participação voluntária. Eles argumentam que as bases da motivação para o voluntariado residem no sentimento de fazer parte de algo ou de transformar um meio. A participação voluntária, por motivos diversos, como o altruísmo ou o egoísmo, deve ser analisada como uma maneira de o indivíduo satisfazer necessidades sociais, como a valorização de si mesmo pelos outros, a interação social e o pensamento pautado na reflexão ou no aspecto de expressão social.

Nesse processo de motivação para o trabalho, os indivíduos construídos socialmente se aliam em processos de significação, que são relacionamentos intersubjetivos e mediados pela interação simbólica. Portanto, defende-se, neste artigo, que a investigação dos motivos para realizar o trabalho deve se iniciar com uma análise do contexto social dos trabalhadores. 
De outra maneira, todo um universo de significados, que, por definição, não são facilmente perceptíveis, permanece oculto, resistente a qualquer intervenção, subtraído de qualquer diagnóstico (Carrieri \& Saraiva, 2007). Tendo em vista uma análise mais aprofundada da relação motivação-trabalhador, é necessária uma reflexão para entender os aspectos subjetivos que envolvem o contexto social do voluntário ao exercer seu trabalho no terceiro setor (Campos \& Saraiva, 20II).

\section{O OLHAR INTERPRETATIVO NA MOTIVAÇÃO PARA O TRABALHO VOLUNTÁRIO}

Com o crescimento do terceiro setor, amplia-se a necessidade de compreender como as relações de trabalho se processam em suas organizações. Em tais instituições sociais, além de haver relações de trabalho tradicionais, como em qualquer organização, é comum existirem também trabalhadores voluntários. Para eles, esse tipo de organização envolve relações de trabalho e motivações específicas (Cavalcanti \& Medeiros, 20II), que são o foco deste artigo.

Cavalcanti et al. (20II) explicam que, para a Organização das Nações Unidas (ONU), o voluntário é a pessoa que, de acordo com seu interesse e a partir do seu espírito cívico, dedica-se a diversas atividades sem uma percepção financeira. Já de acordo com a Lei n. 9.608, de I8 fevereiro de i998, o trabalho voluntário é a realização de uma tarefa sem remuneração, para uma instituição sem fins lucrativos, que englobe objetivos culturais, cívicos, científicos, educacionais, de assistência social ou recreativos. Além disso, tal relação não envolve vínculo empregatício, obrigação previdenciária ou de natureza dos direitos do trabalhador.

Como fenômeno cultural e econômico, o voluntariado faz parte do modo como as sociedades se organizam, de como atribuem responsabilidades sociais e do quanto de engajamento e participação é esperado de seus cidadãos. Assim, as características do trabalho voluntário são um bem social que têm mudado com o tempo, variando de acordo com o contexto cultural e político.

Cnaan e Cascio (I998) propõem que não é possível aprender sobre o trabalho voluntário a partir do conhecimento já existente de trabalhadores remunerados. Segundo os autores, o foco dos voluntários estaria no campo das recompensas simbólicas, associadas a critérios como o comprometimento e o desempenho. Portanto, a gestão de voluntários deve envolver, primordialmente, os investimentos em orientação, supervisão de pessoal e reconhecimento do voluntário.

Com a relevância e o crescimento do terceiro setor na comunidade civil, estudos sobre trabalho voluntário e seus processos são necessários e importantes. 
O voluntário, conforme autores como Cavalcanti et al. (20II) e Cavalcanti e Medeiros (20II), exerce o trabalho com a isenção de renda ou recompensa material, cujas recompensas adquiridas são intangíveis, como a satisfação em participar de um grupo com objetivos semelhantes ou o prazer em ajudar os outros, sendo o serviço uma doação.

Já Bruno e Fiorillo (20I2) apresentam uma abordagem simultânea, atribuindo a influência na motivação do trabalho voluntário a fatores psicológicos intrínsecos e extrínsecos. De acordo com a abordagem de simultaneidade, a oferta de trabalho voluntário deve ser observada com base no papel da motivação psicológica. Os resultados empíricos dos estudos dos autores mostraram que a motivação intrínseca, que envolve aspectos como idade, renda familiar, bem como deveres para com familiares e para com o setor específico em que um indivíduo está envolvido, é uma variável relevante para identificar pessoas, em determinados grupos sociais, com tendências para atuar como voluntárias.

Outro estudo, realizado por Phillips e Phillips (2010), sugere que os gestores de organizações sem fins lucrativos podem se beneficiar oferecendo várias recompensas ou, no mínimo, buscando compreender os desejos dos voluntários ao realizarem o seu trabalho. Os autores propõem que, em organizações sem fins lucrativos, as condições nas quais a motivação dos voluntários ocorre podem ser criadas, por exemplo, ao se comunicar aos voluntários a mensagem simbólica dos ganhos sociais com o trabalho, para que eles associem tal mensagem a uma recompensa: a valorização por parte da organização.

Ao estudarem o aspecto da valorização, entre outros que envolvem o voluntariado, Anheier e Salamon (I999) buscaram entender como esses aspectos se configuram em diferentes partes do mundo, explorando os conceitos e padrões de ação voluntária. O estudo revela pouca diferença sistemática em níveis globais de voluntariado, mas relata níveis mais elevados de atividades de voluntariado na área de serviços sociais e de saúde no caso das mulheres, e nas áreas de esportes, recreação e cultura no caso dos homens. Além disso, a pesquisa evidenciou que o voluntariado é uma prática mais frequente entre os grupos de profissionais com maior renda. Outro resultado foi a variação do trabalho voluntário de acordo com a educação; as pessoas com maior nível educacional se apresentaram como mais propensas a se oferecer para um trabalho voluntário.

Anheier e Salamon (I999) também identificaram três fatores motivacionais que levam as pessoas a ser voluntárias: motivos altruístas, instrumentais e de obrigação. Motivos altruístas incluem noções de um sentimento de solidariedade para com os pobres, quando os voluntários se identificam com as pessoas que sofrem na sociedade e buscam passar esperança e dignidade por meio do seu trabalho. Motivos instrumentais são definidos como um desejo de ganhar novas experiências e habilidades e fazer algo de valor no tempo livre para atender 
as pessoas e também para obter satisfação pessoal como voluntário. Por fim, os motivos de obrigação incluem o dever moral e religioso e um desejo de contribuição para a comunidade local configurado por um sentimento de dever político de trazer mudanças para a sociedade. Os autores sugerem uma estreita ligação entre o aumento dos motivos instrumentais e uma possível mudança de direção do voluntariado, no sentido de uma maior orientação para deixar de ser voluntário. No entanto, essas motivações não podem ser consideradas de maneira isolada, pois raramente ocorrem desse modo, existindo diferentes combinações entre elas (Anheier \& Salamon, I999).

O sentimento de altruísmo como motivação para exercer um trabalho voluntário também ficou evidente nos estudos de Dohme (200I). Contudo, no referido estudo, evidenciou-se que, ainda que inconscientemente, o voluntário busca usufruir algo daquele ofício para sua vida pessoal. A autora explica algumas expectativas dos voluntários ao exercerem seu trabalho, como: oportunidade de utilizar suas habilidades, de se desenvolver pessoalmente, de fazer a diferença na sociedade em que vive e de fazer parte de um grupo. Dohme (200I) parte do princípio de que, ao escolher um trabalho voluntário, a pessoa possui atributos que dão mais qualidade a tarefas como: acrescentar amor ao trabalho, trabalhar em algo que escolheu e de que provavelmente gosta e ser adepto dos objetivos da entidade.

A partir dessas contribuições teóricas, percebe-se que compreender as motivações do trabalho voluntário é um desafio complexo e particularizado e que, para as pessoas em diferentes organizações do terceiro setor, haverá diferentes motivos e desejos em executar determinado trabalho social. Entender o que motiva um indivíduo a fazer parte de um grupo para ajudar outras pessoas demanda um detalhamento particularizado, pois o compromisso está ligado à motivação para escolher uma entre diferentes instituições voluntárias, com características próprias nas suas atividades (Bezerra \& Oliveira, 2007; Cavalcanti \& Medeiros, 20II) e com implicações simbólicas distintas para a motivação do voluntário.

Quando se desenvolve uma análise sob a perspectiva de construção social da realidade (Berger \& Luckmann, I985), almejando tratar da motivação no trabalho voluntário, destaca-se a ênfase à diversidade que envolve os distintos contextos construídos por relações simbólicas específicas. Assim, a construção humana em um dado contexto poderá vir à tona, e, com isso, o pesquisador conseguirá entender as formações socioculturais que envolvem as atitudes dos indivíduos com a organização, e vice-versa, e entender suas relações simbólicas.

Dentro desse corte simbólico, Campos e Saraiva (20II) argumentam que, para tratar adequadamente desse processo, é necessário compreender a maneira como o trabalhador voluntário representa o seu ofício na esfera social, como ele o realiza e os motivos que o levam a trabalhar em um contexto de trabalho sem 
remuneração. Este artigo se volta para esse contexto, com base no interpretativismo simbólico, na busca por compreender os aspectos simbólicos que envolvem a motivação para a realização da tarefa do trabalhador voluntário, por meio dos códigos particulares na interpretação desse contexto (Morgan et al., I983). Para articular empiricamente os argumentos desenvolvidos até aqui em torno da questão de como compreender a motivação no referido contexto, foi realizada uma investigação empírica a partir de aspectos metodológicos apresentados a seguir.

\section{ASPECTOS METODOLÓGICOS}

O objetivo proposto neste estudo se volta para o corte interpretativista, convergente com uma abordagem metodológica qualitativa. A coleta de dados baseou-se nas seguintes técnicas: observação não participante, entrevista semiestruturada e análise de documentos (Flick, 2004).

O locus da pesquisa foi uma das 22 associações voluntárias do Instituto Jutta Batista da Silva (IJBS), a Avapae de Venda Nova do Imigrante, fundada em 2006. A escolha de focar apenas uma organização com um único grupo de voluntárias se justifica, concordando com Triviños (1987), pelo fato de um grupo menor possibilitar maior aprofundamento na análise social em um estudo qualitativo.

A organização foi escolhida em parceria com a equipe técnica do IJBS por ser composta por um maior número de voluntários atuantes e não ter nenhum funcionário contratado. Isso permite focar, na análise, a motivação do trabalho voluntário. Além disso, o grupo de voluntárias da Avapae é considerado pela equipe técnica do IJBS como coeso e dotado de uma boa organização interna, visto como exemplo de trabalho voluntário para as demais associações.

Durante a observação não participante, os dados sobre a vida cotidiana no locus investigado foram registrados em um diário de campo (Cavedon, 2008). A análise de documentos voltou-se para aqueles que tratam da história da Avapae e das normas que regulam a gestão dos voluntários na organização. As entrevistas semiestruturadas permitiram aprofundar o conhecimento sobre questões específicas em relação à motivação e ao núcleo voluntário.

A observação teve lugar durante três meses, entre setembro e novembro de 2013, no local onde as voluntárias se reúnem para realizar suas atividades. As entrevistas foram realizadas aleatoriamente até se chegar a um grupo de entrevistados composto por I2 voluntárias e duas fundadoras da Avapae, quando as informações passaram a se repetir, resultando na chamada saturação de respostas (Bauer \& Aarts, 2002). As características do grupo final de entrevistadas estão no Quadro I. 


\section{QUADRO I}

\section{A LISTAGEM DAS ENTREVISTAS E O CÓDIGO USADO NA ANÁLISE DE DADOS. REGISTRO DAS ENTREVISTAS REALIZADAS COM AS VOLUNTÁRIAS DA AVAPAE}

\begin{tabular}{|c|c|}
\hline ENTREVISTADA & CÓDIGO \\
\hline $\begin{array}{l}\text { Uma das fundadoras da Avapae, atual diretora da Associação } \\
\text { Pró-Hospital Padre Máximo de Venda Nova do Imigrante }\end{array}$ & Fundadora da Avapae 1 \\
\hline $\begin{array}{l}\text { Uma das fundadoras da Avapae e atual superintendente } \\
\text { executiva do IJBS }\end{array}$ & Fundadora da Avapae 2 \\
\hline Voluntária 1, professora aposentada, 54 anos & Voluntária 1 \\
\hline Voluntária 2, dona de casa, 72 anos & Voluntária 2 \\
\hline Voluntária 3, dona de casa, 68 anos & Voluntária 3 \\
\hline Voluntária 4, dona de casa, 66 anos & Voluntária 4 \\
\hline Voluntária 5, dona de casa, 66 anos & Voluntária 5 \\
\hline Voluntária 6, dona de casa, 55 anos & Voluntária 6 \\
\hline Voluntária 7, dona de casa, 64 anos & Voluntária 7 \\
\hline Voluntária 8, empresária no ramo do agroturismo, 59 anos & Voluntária 8 \\
\hline Voluntária 9, professora, 63 anos & Voluntária 9 \\
\hline Voluntária 10, dona de casa, 71 anos & Voluntária 10 \\
\hline Voluntária 11, dona de casa e fundadora da Avapae, 75 anos & Voluntária 11 \\
\hline $\begin{array}{l}\text { Voluntária 12, funcionária da Apae, mobilizadora do voluntariado } \\
\text { no IJBS e diretora da Avapae, } 48 \text { anos }\end{array}$ & Voluntária 12 \\
\hline
\end{tabular}

Fonte: Elaborado pelos autores.

Para tratar dos dados, foi utilizado o método de análise de conteúdo (Bardin, I977) tendo o "tema" como unidade de registro. Durante o tratamento dos dados, buscou-se a diferenciação entre o que era dito e o que aquilo significava de fato, recuperando, assim, as diversas conjunturas das mensagens, uma vez que as análises das mensagens emitidas podem variar de acordo com diversas dimensões de uma unidade de contexto (Franco \& Puglisi, 2003). 
Para a organização dos dados em categorias, foram utilizados os seguintes temas, que emergiram da fala dos emissores: tradicionalismo e religiosidade no voluntariado; o voluntariado como um aprendizado que vem de berço, de família; a associação como um encontro divertido, uma fuga da rotina diária; a diretoria como referência de incentivo e motivação do trabalho; o que distancia o voluntário do trabalho; e a preocupação social por parte das voluntárias ao exercerem seu trabalho.

A partir da organização dos dados com base nos temas, foi feita a interpretação que deu significado às manifestações evidenciadas no contexto do grupo social investigado (Franco \& Puglisi, 2003). A análise apresentada a seguir é resultado dessas interpretações sobre as relações simbólicas que envolvem a motivação do trabalho voluntário na Avapae.

\section{BREVE HISTÓRICO DA AVAPAE}

Em I988, um grupo de famílias venda-novenses uniu-se para criar uma instituição em Venda Nova do Imigrante para cuidar de seus filhos. Essas voluntárias se basearam na ideia e na metodologia que permitiram a criação da então consolidada Associação Pró-Hospital Padre Máximo de Venda Nova do Imigrante. Foi iniciada assim a construção do Clube de Mães, criado para dar apoio a mães que levavam os filhos para serem atendidos no hospital. No clube, as mães aprendiam a fazer artesanato e tinham orientações sobre higiene e cuidados básicos com os filhos.

A Avapae se oficializou em 25 de março de I99I com o nome de Associação de Mães e Voluntárias Amigas dos Excepcionais. Ela passou a receber o apoio do IJBS, transformando-se em uma das suas 22 associações voluntárias existentes atualmente.

No decorrer dos seus 25 anos de existência, a Avapae vem prestando auxílio à Apae de Venda Nova do Imigrante. Os recursos para sua manutenção são provenientes de doações, repasses dos poderes públicos, arrecadações advindas de eventos e festas organizados para esse fim, e receitas provenientes das vendas de donativos em geral e de produtos artesanais confeccionados pelas voluntárias da associação.

No dia a dia, um dos principais papéis das voluntárias é confeccionar artesanatos. A produção segue as orientações do IJBS em projetos de mobilização do voluntariado, de comercialização do artesanato e de revitalização das peças. Hoje a Avapae tem 37 associadas registradas. 


\section{RELAÇÕES SIMBÓLICAS QUE ENVOLVEM A MOTIVAÇÃO DO TRABALHO VOLUNTÁRIO NA AVAPAE}

Durante três meses, no período de setembro a novembro de 2013, os encontros das voluntárias foram observados, e os dados, anotados e registrados em um diário de campo. O número de voluntárias varia entre 15 e 20 mulheres, que chegam por volta do meio-dia e saem aproximadamente às quatro da tarde. Aparentemente, não há controle sobre essa movimentação.

Para cada atividade (bordado, crochê, bainha aberta etc.), há uma pessoa ou um conjunto de pessoas com a habilidade e o desejo de realizá-la. A presidente do IJBS relatou que os trabalhos mais refinados do instituto, como o linho com bainha aberta, são feitos na Avapae e em outra associação também de Venda Nova do Imigrante.

Além da satisfação por esse reconhecimento da qualidade do seu trabalho, nas entrevistas e nas observações, as voluntárias destacaram a alegria e a satisfação relacionadas ao momento de realização dos eventos promovidos pela associação, que são o Chá da Avapae e a Confraternização da Avapae, e pelo IJBS, responsável pelos bazares beneficentes e pela confraternização de fim de ano.

Além desses eventos, que são esporádicos, outros momentos que fazem parte do cotidiano das voluntárias apresentaram-se durante a observação. Eles estão associados a signos e significados relevantes para o entendimento das relações simbólicas nesse grupo social e envolvem motivações relacionadas com a tradição e a religiosidade presentes em laços familiares desde a origem do município de Venda Nova do Imigrante.

\subsection{TRADICIONALISIMO E RELIGIOSIDADE NO VOLUNTARIADO: UM APRENDIZADO QUE VEM DE FAMÍLIA}

As voluntárias manifestaram que, desde a infância, aprenderam com suas famílias que deviam ajudar de alguma forma o próximo e colaborar no desenvolvimento da própria comunidade. Esse processo familiar é marcado pela religiosidade e pela transferência de conhecimentos artesanais específicos, como a arte do bordado, aprendida com as mães e avós. Isso indica a relação entre a história e cultura da família do grupo de mulheres voluntárias e a sua motivação para esse tipo de atividade. Os valores evidenciados por elas no cotidiano estão atrelados à salvação divina, pois, segundo as falas dessas voluntárias, "quem se doa na Terra, pode ganhar o céu, a sua salvação divina”. Tal aspecto vai ao encontro dos estudos 
de Anheier e Salamon (I999), ao demonstrarem que o motivo de obrigação, que inclui o dever moral e religioso, é um dos aspectos relevantes para que uma pessoa exerça um trabalho voluntário.

No tocante à religiosidade, a voluntária 3 ilustra sua importância para as voluntárias da Avapae:

Faço esse trabalho por amor ao próximo. Tem uma frase bonita: "Eu vou ajudar alguém sem saber a quem". Para mim, isso aqui é uma alegria, faço com carinho. Sou católica e preciso ajudar o próximo. Até quando eu puder, eu vou continuar com fé em Deus.

Essa religiosidade faz parte da tradição das famílias de Venda Nova do Imigrante. Mas, especificamente em relação à tradição do trabalho voluntário, a voluntária 8 destaca a relação entre o movimento do voluntariado e o contexto dos moradores do município ao afirmar que o voluntariado "está no nosso sangue da família venda-novense". Essa tradição do voluntariado está na história das famílias de imigrantes que constituíram a cidade, fazendo parte da construção social (Berger \& Luckmann, I985) dessa comunidade.

Nesse sentido, as manifestações evidenciadas externaram que essa preocupação em exercer o trabalho voluntário é algo além da Avapae, pois é uma prática comum entre os moradores do município, atuantes em diferentes tipos de associação voluntária na cidade. A voluntária 8 deixa isso claro em uma de suas falas: "fomos voluntárias na construção do hospital e na diretoria, na construção de igrejas. Toda a família venda-novense está envolvida com o voluntariado". Muitas vezes, as voluntárias trabalham em mais de uma associação, como é o caso da voluntária I, que afirmou o seguinte:

[...] fui a vida toda voluntária: na Pastoral de visita aos doentes, na Pastoral da Saúde, na Igreja. Hoje sou também ministra da Eucaristia e participo aqui na Avapae, na Associação Pró-Hospital Padre Máximo e equipe da coordenação da paróquia.

Manifestações semelhantes foram recorrentes nas entrevistas, o que demonstra um sentimento de altruísmo atribuído aos moradores da cidade.

Por si só, o sentimento de altruísmo associado ao trabalho voluntário não é novidade. O aspecto complementar identificado neste estudo é o escopo desse sentimento na Avapae: no lugar de ser atribuído especificamente ao grupo de voluntários investigado, ele é atribuído a toda comunidade municipal na qual ele se insere. 
Esse sentimento faz parte do que poderia ser chamado de uma cultura propícia ao voluntariado no município de Venda Nova do Imigrante. Segundo as fundadoras da Avapae i e 2, essa cultura no município faz com que as associações voluntárias de Venda Nova ligadas ao IJBS, como a Avapae e a Associação Voluntária Pró-Hospital Padre Máximo, sejam referência de dedicação ao trabalho para as associações do instituto em outros municípios. As fundadoras destacam que isso se deve aos valores que perpassam o convívio na cidade, envolvendo tanto os nativos quanto um novo morador. Segundo as fundadoras:

Quem conviveu com uma família que se dedicou ao voluntariado não tem como não se envolver com o trabalho voluntário. Minhas filhas estão todas envolvidas, somente a que mora longe está menos (fundadora da Avapae 2).

Tem muitas pessoas que estão no voluntariado, mas não são de Venda Nova também. E então o trabalho voluntário vai sendo agregado com essas pessoas que não nasceram aqui, se mudaram pra cá, mas têm o mesmo espírito e participam do voluntariado. Elas se mudam pra Venda Nova e se enquadram direitinho no voluntariado (fundadora da Avapae I).

Aqui cabe destacar uma diferença entre o processo de socialização primária e secundária na construção social da realidade (Berger \& Luckmann, I985). Os nativos já se inserem nessa lógica desde a sua socialização primária, e isso é reforçado pela dinâmica da socialização secundária. É nesse segundo momento que o novo morador se insere na lógica, portanto não se pode afirmar que a relação de ambos os grupos com o contexto da cidade é igual, mas sim que há uma dinâmica na qual ambos são envolvidos por esse contexto de diferentes maneiras. Essa é a dinâmica da construção social do tradicional trabalho voluntário da comunidade venda-novense. A linguagem simbólica das voluntárias, evidenciada durante este estudo, demarca a ordenação na qual esse contexto adquire sentidos e oferece coerência a uma vida cotidiana na qual as pessoas se motivam a vivenciar atividades de doação do seu tempo e trabalho.

Essa motivação se sustenta nos valores presentes no contexto social da cidade de Venda Nova do Imigrante, com destaque para o tradicionalismo e a religiosidade. Segundo os respondentes, essa base foi construída socialmente ao longo da história da cidade, devido às dificuldades de seus antepassados, imigrantes italianos que povoaram a região onde hoje é a cidade. Eles tinham na solidariedade ao próximo um sentido de unidade, pois a cidade foi construída a partir da colaboração entre as famílias. De acordo com a voluntária ıг: 
[...] no início da imigração em Venda Nova do Imigrante, cada família plantava seu café. Quando uma família precisava de ajuda, todos os demais se mobilizavam. Se uma pessoa ficava doente, todos faziam um mutirão para ajudar. Se tinha que abrir uma estrada, juntava todo mundo. É cultural da cidade, sempre foi.

As fundadoras da Avapae explicitaram que, com forte traço religioso de doação, o voluntariado é referência na cidade, como uma tradição passada de geração em geração. Exemplos, como escolas formadas a partir de união de mães voluntárias, a Festa da Polenta e a construção de igrejas e bairros, citados por elas, ocasionaram a efetivação do Dia do Voluntariado na cidade, 9 de outubro, sancionado como projeto de lei em 2013, declarando o voluntariado como patrimônio histórico e cultural da cidade.

De acordo com o Bruno e Fiorillo (20I2), a motivação no trabalho voluntário é influenciada por aspectos psicológicos intrínsecos e aspectos como idade, renda familiar ou deveres familiares. Entretanto, nesta pesquisa, há evidências de que, a despeito de boa parte desses aspectos que configuram o perfil do voluntariado condizer com as características das voluntárias, outro fator relevante para a motivação delas, mas que fica em segundo plano em parte dos estudos, são as construções sociais ao longo de gerações de familiares em dado grupo social. No caso de Venda Nova do Imigrante, evidenciou-se que o desenvolvimento do voluntariado na cidade envolve construções sociais recentes e outras que remetem a várias gerações de familiares.

Esse contexto criou um ambiente propício para o surgimento de interpretações positivas em relação ao momento em que se está atuando no voluntariado. Entre elas, no contexto investigado, destacou-se a interpretação da atividade voluntária como diversão, como uma fuga da rotina diária, que é temporariamente substituída por outra responsabilidade também considerada relevante: ajudar o próximo.

\section{A ASSOCIAÇÃO COMO UM ENCONTRO DIVERTIDO, UMA FUGA DA ROTINA DIÁRIA}

Em sua maioria, as voluntárias da Avapae são donas de casa ou aposentadas e destacaram que o trabalho voluntário é uma fuga da rotina diária de afazeres do lar. Elas saem das tarefas rotineiras para atividades que, segundo elas, são divertidas. Isso revela que há uma busca de satisfação pessoal na doação ao trabalho voluntário que não se restringe ao voluntariado em si, mas que inclui a possibilidade de variar a rotina. É claro que existem alternativas além do trabalho voluntário para se escapar da rotina doméstica, mas, no contexto dessas mulheres, a atividade voluntária é interpretada como socialmente aceitável e defendida. 
Não é uma simples fuga de responsabilidades para obter diversão, é também a troca de um tipo de responsabilidade por outra que atende à necessidade de outras pessoas mais carentes. As manifestações a seguir revelam esses aspectos:

Vir para a Avapae significa sair de uma prisão e vir para uma grande festa [...]. Sinto essa necessidade de sair, só gosto de ficar em casa meio horário; no outro, tenho que sair (voluntária I).

Isso aqui me faz bem, é saúde. A gente conversa com todo mundo, brinca, conta piada, descontrai. Aqui passo essas horas maravilhosas, e venho, faço os trabalhos para ajudar os outros. Tudo me faz querer continuar. Isso aqui é tudo para mim (voluntária 3).

Eu sinto que, quando eu não venho, que tem alguma coisa me faltando, sinto falta quando não venho. É muito gratificante estar com as colegas, quando você chega, esse ambiente de trabalho agradável. Você chega aqui, começa a fazer as coisas e esquece de tudo. Depois tem a gratificação com o trabalho, em saber que você está ajudando alguém (voluntária 6).

Essa atratividade do trabalho voluntário, simbolizada pela diversão e saída da rotina, em conjunto com o altruísmo, vai ao encontro dos estudos de Sampaio e Morávia (2009), que concluíram que a motivação do trabalho voluntário está baseada em compensações intangíveis. Tal afirmação também condiz com o estudo de Sampaio (2004), que resultou no entendimento de que o trabalho voluntário é uma busca por desligar-se de sofrimentos e de problemas de outros contextos sociais, sendo um alívio, uma fonte de prazer.

Portanto, ser voluntário na Avapae significa também usufruir de algo relacionado com o aspecto pessoal no trabalho, como fazer parte de um grupo, ter uma ocupação e ter amigos, bem como participar de encontros e confraternizações. Dessa maneira, de acordo com Spink (I995), o pensar individual dos trabalhadores, seus desejos e necessidades se entrecruzam no ambiente organizacional por meio das práticas sociais. A partir disso, o individual e o social se misturam, influenciam-se mutuamente, remetendo as pessoas a identificar motivos, como a busca pela diversão e pela quebra da rotina, para se engajarem no trabalho voluntário em uma dada organização. No caso da Avapae, a organização explora deliberadamente esses aspectos, no sentido de colaborar para que se estabeleça um ambiente interno propício a essas construções sociais em torno de motivações para trabalhar voluntariamente. 


\subsection{A DIRETORIA COMO REFERÊNCIA DE INCENTIVO E MOTIVAÇÃO DO TRABALHO}

Desde o início da coleta de dados, percebeu-se que a diretora da Avapae demonstrava muita preocupação com o acabamento dos trabalhos realizados, servindo como exemplo para as demais voluntárias de uma pessoa voltada para a realização de um trabalho cada vez melhor. Ao longo das semanas de observação, isso ficou evidente, assim como o reconhecimento das demais voluntárias à importância desse tipo de postura, mesmo quando isso significava serem advertidas pela diretora com manifestações como: "hoje teve muita brincadeira" (voluntária I2) ou "precisam ter comprometimento com o trabalho voluntário também e não fazerem o trabalho como se fosse uma terapia, e sim com dedicação" (voluntária I2).

Isso revela o esmero exigido das voluntárias, cujo resultado é percebido pela concentração que elas têm em seus bordados e ainda pelo fato de levarem trabalhos para casa a fim de terminá-los durante a semana.

Segundo Skinner (1997) e Rey (2005), essa convergência de interesses gera motivações para que os trabalhadores acreditem nos ideais da organização em que trabalham e se envolvam com eles. Para a diretora se inserir nessa lógica da convergência de interesses, sendo elogiada pelo grupo de voluntárias, e alcançar o intuito de direcionar suas energias aos objetivos da Avapae, houve um processo de construção social entre elas que não é instrumentalizável em termos da construção em si. Isso não impede, porém, que os resultados dessa construção sejam instrumentalizáveis no sentido de o grupo social estabelecer subjetivamente objetivos convergentes com os da Avapae. Segundo as voluntárias:

Todos os momentos são importantes, aqui nos bordados ou nos eventos do IJBS - o acolhimento é muito legal com os voluntários, e isso me motiva a continuar meu trabalho. Incentivo que vem da gestão, que tenho mais contato. Temos dois eventos aqui, um chá e a confraternização de fim de ano que a diretoria promove, e todas voluntárias adoram (voluntária 9).

Minha mãe sempre me ensinou: fazer o bem sem olhar a quem. Não importa quem está sendo ajudado, mas que o dinheiro está sendo bem investido, e eu confio na diretoria da associação (voluntária I).

O momento do café, que ocorre em todos os dias de atividades da associação, exemplifica essa articulação subjetiva que envolve as voluntárias, a diretora, 
que também é voluntária, e os interesses da Avapae. É um momento no qual se evidencia o contexto sendo realizado e comunicado principalmente por meio de símbolos e das relações sociais construídas (Gioia, I986). As voluntárias reúnem-se em volta da mesa de café. Então, elas começam a colocar as intenções da reza e depois rezam orações católicas. Depois que rezam, comem as guloseimas, e uma voluntária vai anotando em um livro o nome de quem está presente, uma forma de registro, mas que é transformada em uma brincadeira de sorteios de prendas. O livro de sorteio e a premiação são aspectos que simbolizam o envolvimento das voluntárias com seu trabalho na Avapae.

A presidente relata que esse costume do momento do café, de rezar e dos sorteios foi inspirado na rotina de encontros da Associação das Voluntárias Pró-Hospital Padre Máximo e hoje é disseminado como um meio de promover a integração para as demais associações apoiadas pelo IJBS. Aqui, novamente, observam-se manifestações do tradicionalismo e da religiosidade entre as voluntárias da Avapae.

Evidencia-se que as motivações para essas voluntárias são articuladas em valores e significados associados a diversos tipos de recompensa. Os elogios e as orientações da diretoria, o significado de ajudar o próximo, a possibilidade de expressar sua religiosidade, os momentos lúdicos dos sorteios e brincadeiras, a fuga da rotina, a manutenção das tradições familiares e sociais, em conjunto, configuram as motivações dessas mulheres. Esse entendimento vai ao encontro dos estudos de Cnaan e Cascio (1998) e Phillips e Phillips (2010), que diagnosticaram que os trabalhadores voluntários se motivam por recompensas simbólicas. Entretanto, deve ficar claro que as articulações simbólicas não se limitam a construções que levam à motivação para o trabalho voluntário, pode ocorrer o oposto, a desmotivação, e tais elementos também foram identificados na Avapae.

\section{8 .4 A DESMOTIVAÇÃO PARA O TRABALHO VOLUNTÁRIO NA AVAPAE}

Há evidências de desinteresse das voluntárias na participação da parte burocrática da Avapae, pois tais atividades são associadas a significados pejorativos e vistas como indesejáveis, ao contrário de outras atividades interpretadas como agradáveis, como bordar. Segundo a voluntária I2,

[...] se você perceber bem, a diretoria está sempre trocando de função justamente por isso. Não se pode exigir muito de uma pessoa de 70 anos, elas querem fazer o que gostam, que é bordar. Portanto, isso ocasiona a necessidade de um revezamento entre as mesmas pessoas na diretoria, ocupando cargos diferentes. 
Outro ponto de desinteresse envolve os cursos oferecidos pelo instituto, pois sempre as mesmas pessoas da Avapae participam. De acordo com a voluntária I2, o problema tem relação com o caráter mais técnico desses cursos, o que, segundo ela, afasta as demais voluntárias.

Já quando questionadas sobre o que poderia causar ou já causou a vontade de parar com as atividades do trabalho voluntário na associação, as respostas se direcionavam para o quanto a sua condição física e de saúde poderia aguentar. Várias respondentes destacaram a condição física como o seu maior limitador, conforme ilustrado a seguir:

As atividades que eu faço aqui são o crochê, o biquinho, apesar de minhas dores no braço. Enquanto eu aguentar, venho e faço. Nunca pensei em desistir desse trabalho, mesmo quando tive que fazer cirurgia no braço; assim que o médico liberou, eu já estava aqui de novo (voluntária 2).

Deus me dando força, eu quero continuar. Só essa dor no braço que incomoda um pouco e dificulta, mas Deus me dando força, vou continuar (voluntária 3).

Quero chegar até quando minha força der, quando eu puder. Meu objetivo e ajudar os mais carentes. Só parei quando fiz cirurgia (voluntária Io).

Esse aspecto também ficou evidente quando, durante as observações, percebeu-se que elas reclamavam de dores, paravam para se esticar, por não aguentarem ficar muito tempo na mesma posição, fazendo as mesmas repetições que os bordados exigiam. Em uma segunda-feira, a voluntária I apareceu na associação com o braço direito todo enfaixado. Quando a pesquisadora perguntou o que havia acontecido, ela respondeu que era de tanto bordar, o que causou um constrangimento em todas as outras voluntárias, mas, mesmo assim, a voluntária estava lá. Ou seja, as limitações físicas se manifestaram como o único aspecto associado ao sentido de parar com o trabalho voluntário na Avapae, mas, na prática, mesmo quando essa parada efetivamente ocorria, era algo temporário.

Essa interpretação e as demais discutidas até aqui fazem parte de um conjunto de construções sociais que envolve a dinâmica das motivações no trabalho voluntário na Avapae. Uma parte dessa dinâmica se mostrou também relacionada às influências das construções simbólicas dos moradores da cidade em que a Avapae atua, Venda Nova do Imigrante. 


\section{CONSIDERAÇÕES FINAIS}

Com base na análise dos dados, evidenciou-se que a compreensão das motivações para o trabalho voluntário é um desafio complexo e particularizado, permeado por múltiplas construções sociais. A possibilidade de essas construções sociais variarem entre organizações contribui para o entendimento de que, em cada organização, há diferentes motivos e desejos relacionados à execução de um trabalho voluntário (Bezerra \& Oliveira, 2007).

Para o grupo estudado, a importância do trabalho voluntário surgiu atrelada à capacidade de, por meio de um bordado, por exemplo, produzir significados, como aqueles relacionados a ajudar o próximo, manter a tradição do voluntariado, divertir-se e mudar a rotina, atender às obrigações religiosas, entre outros. Esses significados envolvem o fato de o trabalho voluntário dessas mulheres ser o elo de parte de suas relações sociais e representar o papel delas na sociedade em que vivem, visto que ser voluntária em Venda Nova tem um significado relevante, de prestígio social. A voluntária, antes de ser uma trabalhadora na Avapae, pertence a um grupo social, no qual passou por processos de construção de valores e crenças e de socialização (Campos \& Saraiva, 20II).

De acordo com Palassi \& Vervloet (20II), a motivação por meio dos significados da participação voluntária tem como base o sentimento de fazer parte de algo ou transformar um meio, com o sentido de ser importante naquela tarefa social. Isso vai ao encontro dos sentimentos dessas voluntárias, que demonstram, pelos dados coletados, estar realizadas ao exercerem seu trabalho. Tal realização ocorre não só em virtude de fazerem parte da Avapae, mas também por fazerem parte da Avapae em Venda Nova do Imigrante. O contexto social da organização e do município no qual ela se insere destacou-se como imbricado na dinâmica da motivação das voluntárias.

As construções sociais na Avapae tomam contornos organizativos do espaço simbólico, em que há processos de produção de sentido para as voluntárias por meio do rearranjo de suas histórias sociais subjetivas que se entrelaçam em torno do valor de ser voluntário naquele ambiente social. Somado a isso, o novato na Avapae ou em Venda Nova do Imigrante se entrelaça e se reconstrói naquele meio propício ao voluntariado. Esse novo integrante está em um contexto propício para reconhecer os hábitos, os valores e as imagens que contribuem para motivar a realização do trabalho voluntário.

Portanto, a pesquisa chega a resultados que evidenciam o meio social como produtor e, ao mesmo tempo, produto dos atores sociais que ali se constroem e são construídos. Tal entendimento ajusta-se às propostas sobre a construção social da realidade (Berger \& Luckmann, I985), a subjetividade (Rey, 2005) e seus 
entrelaçamentos com o simbolismo organizacional (Morgan et al., I983; Gioia, I986; Carrieri \& Saraiva, 2007). Ao trazer essas contribuições para o campo dos estudos sobre a motivação no trabalho voluntário, esta pesquisa preenche uma lacuna no sentido de posicionar as construções sociais como um aspecto relevante do processo motivacional no trabalho voluntário.

Esse entendimento permite propor que estudos futuros busquem compreender a relação entre os aspectos simbólicos, foco deste artigo, e outros aspectos objetivos, como a renda e a idade, que também são associados à motivação no trabalho voluntário. Como contribuição final deste trabalho, defende-se que os caminhos para tratar dessas questões devem considerar a ação dos atores sociais e os seus contextos de inserção, em termos das trocas simbólicas vivenciadas na organização e na sociedade mais ampla, como foi observado na comunidade venda-novense.

\section{SYMBOLIC RELATIONSHIPS AND MOTIVATION IN VOLUNTEER WORK}

\section{ABSTRACT}

The purpose of this article is grasping the symbolic relationships that involve motivation in volunteer work. The locus of the empirical portion of this article is the Associação Voluntária da Apae (Avapae) in Venda Nova do Imigrante, Brazil. The article legitimizes the relevance of studying organizations through approaches focused on organizational symbolism (Morgan, Frost \& Pondy, I983; Gioia, I986; Carrieri \& Saraiva, 2007). This is done herein by recognizing the relationships between the social construction of volunteers' reality (Berger \& Luckmann, I985) and their representations of motivation based on a subjectivity (Rey, 2005) connected to the particularities of volunteer work. Empirical data were collected by means of semi-structured interviews with i4 Avapae volunteers, a 3-month non-participant observation period at the volunteers' workplace, and documentary analysis. Data were processed by using the content analysis technique. According to volunteers, work is related to the capacity of, through an embroidery, for instance, producing meanings, such as helping others, having fun, and changing the routine, among others. Motivation, observed through the meanings attached to volunteer work, is based on the feeling of being part of something or changing a way, in the sense of playing a significant role in relation to that social task (Palassi \& Vervloet, 20II). The investigation showed the context of Avapae as complex, permeated by symbolism and multiple subjectivities, 
especially concerning the social constructions of people living in Venda Nova do Imigrante, in addition to the limits of the organization studied. 'Venda-novenses' emerged as a product and producer of the symbolism surrounding the motivation for volunteering. As a final contribution of this study, we argue that the ways to address volunteers' motivation must consider the actions of these social agents and their insertion contexts in terms of the symbolic exchanges experienced within the organization and society as a whole, as it has been observed within the 'venda-novense' community.

\section{KEYWORDS}

Organizational symbolism. Motivation. Work. Volunteer. Subjectivity.

\section{LAS RELACIONES SIMBÓLICAS Y LA MOTIVACIÓN EN EL TRABAJO VOLUNTARIO}

\section{RESUMEN}

El propósito de este artículo es entender las relaciones simbólicas que involucran la motivación en el trabajo voluntario. La parte empírica del artículo fue desarrollada en la Associação Voluntária da Apae (Avapae) de Venda Nova do Imigrante, Brasil. El artículo se legitima por la relevancia del estudio de las organizaciones a través de enfoques centrados en el simbolismo organizacional (Morgan, Frost \& Pondy, I983; Gioia, I986; Carrieri \& Saraiva, 2007). El artículo se basa en el reconocimiento de la relación entre la construcción social de la realidad (Berger \& Luckmann, I985) de los voluntarios y sus representaciones de la motivación que envuelven una subjetividad (Rey, 2005) que se articula en los aspectos específicos del trabajo voluntario. Los datos empíricos fueron recolectados a través de entrevistas semi-estructuradas con I4 voluntarios de Avapae, de observación no participante durante tres meses en el local de trabajo de los voluntarios y de análisis de documentos. Los datos fueron analizados con la técnica de análisis de contenido. Para las entrevistadas, el trabajo está relacionado con la capacidad de, mediante un trabajo de artesanía, producirse significados, cómo ayudar a los demás, divertirse y cambiar la rutina, entre otros. Se observó que la motivación a través de los significados de la participación voluntaria se basa en la sensación de ser parte de algo o hacer un camino en un sentido ser importante en el entorno social (Palassi \& Vervloet, 20II). La investigación ha mostrado que el contexto de Avapae es complejo, impregnado de simbolismo y múltiples subjetividades, 
especialmente los de las construcciones sociales de los residentes de Venda Nova do Imigrante, fuera de la organización estudiada. El "venda-novense" surgió como producto y productor del simbolismo que rodea a la motivación para el voluntariado. Como contribución final del trabajo, se argumenta que las formas de abordar la motivación para el voluntariado deberían considerar la acción de estos actores sociales y sus contextos de inserción, mediante intercambios simbólicos en la organización y en la sociedad en general, como se ha percibido en la comunidad "venda-novense".

\section{palabras clave}

Simbolismo organizacional. Motivación. Trabajo. Voluntario. Subjetividad.

\section{REFERÊNCIAS}

Aktouf, O. (1994). O simbolismo e a cultura de empresa. In J. F. Chanlat (Org.). O indivíduo nas organizações: dimensões esquecidas (Vol. 2, pp. 39-79). São Paulo: Atlas.

Anheier, K. H., \& Salamon, L. M. (I999). Volunteering in cross-national perspective: initial comparisons, law and contemporary problems. Law and Contemporary problems, 62(4), 43-65.

Balsan, L. A. G., Campos A. P., \& Fossá, M. I. T. (20II, novembro). Investigando os motivos que levam a trabalhar: um estudo em uma instituição federal de ensino. Anais do Encontro de Gestão de Pessoas e Relações de Trabalho da Anpad, João Pessoa, PB, Brasil, 3.

Bardin, L. (I977). Análise de conteúdo. Lisboa: Edições 70.

Bastos, A. V. B., Brandão, M. G. A., \& Pinho, A. P. M. (I997). Comprometimento organizacional: uma análise do conceito expresso por servidores universitários no cotidiano de trabalho. Revista de Administração Contemporânea, 2(I), 97-I20.

Bauer, M. W., \& Aarts, B. A. (2002). A construção do corpus: um princípio para a coleta de dados qualitativos. In W. Bauer \& G. Gaskell. Pesquisa qualitativa com texto, imagem e som (pp. 39-63). Rio de Janeiro: Vozes.

Berger, P. L., \& Luckmann, T. (1985). A construção social da realidade. Petrópolis: Vozes.

Bezerra, R. M. M., \& Oliveira, F. C. (2007, junho). Fatores que geram a evasão no trabalho voluntário. Anais do Encontro de Gestão de Pessoas e Relações de Trabalho da Anpad, Natal, RN, Brasil, I.

Bruno, B., \& Fiorillo, D. (20I2). Why without pay? Intrinsic motivation in the unpaid labour supply. The Journal of Socio-Economics, 41(5), 659-669.

Burrell, G., \& Morgan, G. (I979). Sociological paradigms and organizational analysis: elements of the Sociology of corporate life. London: Heinemann.

Campos, M., \& Saraiva, L. A. S. (20II, novembro). Representações sociais e sentido do trabalho. Anais do Encontro de Gestão de Pessoas e Relações de Trabalho da Anpad, João Pessoa, PB, Brasil, 3. Carrieri, A. de P., \& Saraiva, L. A. S. (2007). Introdução. In A. de P. Carrieri \& L. A. S. Saraiva (Orgs.). Simbolismo organizacional (pp. I-I2). São Paulo: Atlas. 
Cavalcanti, C. E., Medeiros, C. A. F. (20II, setembro). Desenho do trabalho voluntário e comprometimento organizacional: um estudo nas organizações não governamentais. Anais do Encontro Nacional da Associação Nacional de Pós-Graduação e Pesquisa em Administração, Rio de Janeiro, RJ, Brasil, 36.

Cavalcanti, C. E., Medeiros, C. A. F., Moreira Neto, J. A., Oliveira, J. A., \& Souza, W. J. (20II). No trabalho voluntário: estudo das relações entre comprometimento organizacional e desenho do trabalho em ONGs. Revista Estudos do Cepe, 33, 206-230.

Cavedon, N. R. (2008). Antropologia para administradores. Porto Alegre: UFRGS.

Cavedon, N. R., \& Fachin, R. C. (2008). Homogeneidade versus heterogeneidade cultural: um estudo em uma universidade pública. In A. de P. Carrieri, N. R. Cavedon \& A. R. L. da Silva (Orgs.). Cultura nas organizações (pp. 35-58). Curitiba: Juruá.

Cnaan, A. R., \& Cascio, T. (I998). Performance and commitment: issues in management of volunteers in human service organizations. Journal of Social Service Research, 24, I-37.

Dohme, V. (200I). Voluntariado: equipes produtivas. Como liderar ou fazer parte de uma delas. São Paulo: Editora Mackenzie.

Flick, U. (2004). Uma introdução à pesquisa qualitativa. Porto Alegre: Bookman.

França, A., Mendes, A. M., \& Siqueira, V. S. Discurso organizacional e instrumentalização do prazer no trabalho. Anais do Encontro de Gestão de Pessoas e Relações de Trabalho, Curitiba, PR, Brasil, 3, $201 \mathrm{II}$.

Franco, B., \& Puglisi, M. L. (2003). Análise de conteúdo. Brasília: Plano.

Gioia, D. A. (I986). Symbols, scripts, and sensemaking: creating meaning in the organizational experience. In H. P. Sims \& D. A. Gioia (Eds.). The thinking organization (pp. 49-74). San Francisco: Jossey-Bass Publishers.

Herzberg, F. (1997). Mais uma vez: como motivar seus funcionários. In V. H. Vroom (Org.). Gestão de pessoas, não de pessoal (pp. 55-82). Rio de Janeiro: Campos.

Jaime, P., Jr. (2005). Um texto, múltiplas interpretações: antropologia hermenêutica e cultura organizacional. In N. R. Cavedon \& J. Lengler (Orgs.). Pós-modernidade e etnografia nas organizações (pp. I45-169). Santa Cruz do Sul: Edunisc.

Maslow, A. H. (I970). Introdução à psicologia do ser. Rio de Janeiro: Eldorado.

McClelland, D. C. (I953). The achievement motive. New York: Appleton Century Crofts.

McGregor, D. (I970). Os aspectos humanos na empresa. Lisboa: LCE Clássica.

Morgan, G., Frost, P., \& Pondy, L. (1983). Organizational symbolism. In T. C. Dandridge, P. J. Frost, G. Morgan \& L. Pondy. Organizational symbolism (pp. 3-35). Connecticut: Jay Press; London: Jain Press.

Nord, W. R., \& Fox, S. (2004). O indivíduo nos estudos organizacionais: o grande ato de desaparecimento? In S. R. Clegg, C. Hardy \& W. R. Nord (Eds.). Handbook de estudos organizacionais (Vol. 3, pp. I86-225). São Paulo: Atlas.

Paes De Paula, A., P., \& Palassi, M. P. (2007). Subjetividade e simbolismo nos estudos organizacionais. In A. P. Carrieri \& L. A. S. Saraiva (Orgs.). Simbolismo organizacional (pp. 199-228). São Paulo: Atlas.

Palassi, M. P., \& Vervloet, A. M. P. (20II). Eleições, mesários e subjetividade: reflexões sobre a produção de sentidos subjetivos a partir da participação voluntária no processo de votação. Psicologia e Sociedade, 23(2), 3I2-324. 
Penna, G. A. (200I). Introdução à motivação e emoção. Rio de Janeiro: Imago.

Phillips, L. C., \& Phillips, M. H. (20I0). Volunteer motivation and reward preference: an empirical study of volunteerism in a large, not-for-profit organization. SAM Advanced Management Journal, 75(4), I2-I9.

Rey, F. G. (2005). Pesquisa qualitativa e subjetividade: os processos de construção da informação. São Paulo: Thomson.

Sampaio, J. R. (2004). Voluntários: um estudo sobre motivação das pessoas e a cultura em uma organização do terceiro setor. Tese de doutorado, Universidade de São Paulo, São Paulo, SP, Brasil.

Sampaio, J. R., \& Morávia, C. B. (2009, novembro). Motivação de voluntários em creche do terceiro setor. Anais do Encontro de Gestão de Pessoas e Relações de Trabalho da Anpad, Curitiba, PR, Brasil, 2. Saraiva, L. A. S. (2007). A cultura como fenômeno econômico e simbólico. In A. P. Carrieri \& L. A. S. Saraiva (Orgs.). Simbolismo organizacional (pp. 13-34). São Paulo: Atlas.

Skinner, W. (I997). Muito chapéu para pouco gado: gestão de recursos humanos. In V. H. Vroom. Gestão de pessoas, não de pessoal (pp. 3-19). Rio de Janeiro: Campos.

Spink, M. J. (I995). O conhecimento do cotidiano: as representações sociais na perspectiva da psicologia social. São Paulo: Brasiliense.

Triviños, A. N. S. (I987). Introdução à pesquisa em ciências sociais: a pesquisa qualitativa em educação. São Paulo: Atlas.

Turner, B. A. (I990). Introduction. In A. B. Turner (Ed.). Organizational symbolism (pp. I-II). New York: De Gruyter. 